\title{
Taxa de desidratação e composição químico-bromatológica do feno de grama-estrela (Cynodon nlemfuensis Vanderyst) em função de níveis de adubação nitrogenada
}

\section{Dehydratation rate and chemical composition of stargrass (Cynodon nlemfuensis Vanderyst) hay as a function of nitrogen fertilization}

\author{
Moysés Calixto Júnior ${ }^{1 *}$; Clóves Cabreira Jobim²; Marcos Weber do Canto ${ }^{3}$
}

Resumo

O objetivo do trabalho foi determinar a taxa de desidratação da forragem após o corte, em condições de campo e avaliar a composição química em função da adubação nitrogenada. Utilizou-se dois níveis de adubação (50 e $100 \mathrm{Kg} / \mathrm{N} / \mathrm{ha}$ ) com o corte realizado após 28 dias de crescimento. Durante o período de secagem a campo foram realizadas amostragens no momento do corte e mais outras sete após o corte, para determinar a taxa de desidratação da planta e das frações folha e colmo. O delineamento experimental foi inteiramente casualizado com dez repetições e os dados de composição química, comparados pelo teste F (5\%). A velocidade de perda de água foi maior para a folha comparada ao colmo, mostrando o mesmo padrão para os dois níveis de adubação. Na avaliação da composição química, a PB diferiu $(\mathrm{P}<0,05)$ quanto ao nível de nitrogênio. As concentrações de FDN, FDA, EE e MM não apresentaram diferença $(\mathrm{P}>0,05)$ para o nível de nitrogênio. Da mesma forma, para a DIVMS e DIVPB não houve efeito $(\mathrm{P}>0,05)$ entre os níveis de adubação nitrogenada. A adubação nitrogenada proporcionou aumento no teor de PB do feno de grama-estrela, porém não afetou os componentes da fibra, não resultando em aumento na qualidade nutricional do feno.

Palavras-chave: Digestibilidade, fibra, forragem, proteína

\begin{abstract}
The objective of this study was to determine the dehydratation rate of after-harvest forage in the field conditions and to evaluate the chemical composition as a function of nitrogen fertilization. It was used two fertilization levels (50 and $100 \mathrm{~kg} / \mathrm{N} / \mathrm{ha}$ ) and forage was harvest with 28 days growth. During field wilting, one sample at harvest time and seven others after it were collected to determine the dehydratation rate of the whole plant and the leaf and stem fractions. A completely randomized experimental design with ten replications was used, and the chemical composition data were compared by F Test (5\%). The water loss rate was higher for leaf when compared to stem fraction, showing the same pattern for both fertilization levels. In chemical composition evaluations, crude protein $(\mathrm{CP})$ was different $(\mathrm{P}<0.05)$ for the two nitrogen levels, while the NDF, ADF, EE and MM concentrations did not show differences $(\mathrm{P}>0.05)$. In vitro dry matter digestibility (INDMD) and in vitro crude protein digestibility (INCPD) were not affected $(\mathrm{P}>0.05)$ by the levels of nitrogen fertilization. Nitrogen fertilization increased the CP concentration in Stargrass hay, but did not affect the fiber fraction, not increasing the nutritional quality of hay.

Key words: Digestibility, fiber, forage, protein
\end{abstract}

\footnotetext{
1 Aluno de Mestrado do Programa de Pós-Graduação em Zootecnia da UEM.

2 Prof. Associado do Departamento de Zootecnia da UEM.

3 Prof. Adjunto do Departamento de Zootecnia da UEM.

* Autor para correspondência
} 


\section{Introdução}

A forragem disponível nas pastagens durante o período seco não contém todos os nutrientes essenciais, na proporção adequada, para atender integralmente as exigências dos animais em pastejo. Desta forma, é de suma importância a produção de forragem de alta qualidade para a produção de fenos de elevado valor nutritivo durante o verão, resultando em eficiente utilização deste recurso forrageiro para suprir as deficiências quantitativas e qualitativas observadas durante o período de seca.

As forrageiras sub-tropicais e tropicais podem produzir fenos de boa qualidade ( 8,0 a $12 \%$ de PB e 55 a $60 \%$ de digestibilidade) em condições climáticas adequadas e bom manejo no processo de fenação. Entretanto, a maioria dos fenos produzidos no Brasil apresentam qualidade inferior (6 a 7\% de PB e 45 a $50 \%$ de digestibilidade), devido à pouca difusão das técnicas mais adequadas para sua produção (GOMIDE, 1980).

O princípio básico da fenação, resume-se na conservação do valor nutritivo da forragem por meio da rápida desidratação, uma vez que a atividade respiratória das plantas, bem como dos microorganismos é paralisada. As perdas no processo de fenação tem alta correlação com o tempo de secagem. Assim sendo, uma rápida desidratação pode manter a qualidade da forragem resultando em feno de bom valor nutritivo.

O processo de fenação implica em exportação contínua de nutrientes da área, levando ao rápido esgotamento do solo se não repostos adequadamente. Atenção especial deve ser dada para os níveis de fósforo $(\mathrm{P})$, nitrogênio $(\mathrm{N})$ e potássio $(\mathrm{K})$, três dos macrominerais mais importantes para a forragem a ser fenada. $\mathrm{O}$ nitrogênio e o potássio devem ter reposição fracionada pelo número de cortes para permitir máxima eficiência de aproveitamento (HADDAD; CASTRO, 1998).

Devido à grande remoção de nitrogênio em forragens conservadas, Werner (1984) recomenda adubação nitrogenada na base de $2 \%$ de $\mathrm{N}$ da quantidade de material removido na forma de feno. No entanto, a estratégia de adubação deve ser definida pelo manejador, seguindo a logística de manejo, produtividade da área e tipo de solo.

A qualidade de uma planta forrageira depende de seus constituintes químicos e esses são variáveis, dentro de uma mesma espécie, de acordo com a idade e parte da planta, fertilidade do solo, fertilização recebida, entre outros (VAN SOEST, 1994).

Quando se adubam as pastagens com nitrogênio pode ocorrer uma variação na composição química da matéria seca das plantas. Geralmente o nitrogênio pode provocar um incremento no teor da $\mathrm{PB}$ e melhora na DIVMS, através do aumento da participação da matéria seca de folhas na matéria seca total da planta. Entretanto, Van Soest (1994) afirma que, em determinadas situações, a fertilização nitrogenada tende a reduzir a digestibilidade das plantas forrageiras e esse fato está relacionado com o aumento nos compostos nitrogenados, acompanhado do aumento dos compostos da parede celular e da redução nos carboidratos solúveis, fração que é $100 \%$ digestível. Para a fração fibra em detergente ácido e fibra em detergente neutro, a aplicação de nitrogênio promove um incremento no acúmulo de tecidos fibrosos, e conseqüentemente uma elevação no percentual destes na MS das plantas (CECATO, 1993).

Martim (1997) observou decréscimo nos teores de FDN dos cultivares Coast-cross e Tifton 85 em função da adubação nitrogenada. No primeiro corte, a média dos teores de FDN para os dois capins reduziu de $69,1 \%$ para $67,65 \%$ e, no segundo corte, de $71,32 \%$ para $69,9 \%$, respectivamente, nas doses de 20 e 180 $\mathrm{Kg}$ de N/ha.

A digestibilidade in vitro simula a digestão no trato gástrico dos ruminantes, permitindo se fazer estimativas de digestibilidade da matéria seca ou orgânica, e os resultados obtidos permitem estimar o consumo dos animais em pastejo. 
Em trabalho realizado com Tifton 85, Tifton 44 e Coastal sob um regime de corte, a cada quatro semanas, em parcelas adubadas com $200 \mathrm{Kg} \mathrm{N} / \mathrm{ha} / \mathrm{ano}$, Hill, Gates e Burton (1993) encontraram valores de digestibilidade in vitro da matéria seca de $60,3 \%, 55,0 \%$ e $54,3 \%$, para as respectivas gramíneas estudadas.

Assis (1997) não observou efeito para as duas doses de nitrogênio ( 0 e $400 \mathrm{Kg} / \mathrm{ha}$ ) sob quatro cortes com intervalo de 35 dias, sobre a digestibilidade das gramas Estrela de Porto Rico e Estrela Roxa. O coeficiente de DIVMS para a Estrela de Porto Rico foi de 62,47 e 61,24 e, para a Roxa, de 62,53 e 63,54, respectivamente para as doses de 0 e $400 \mathrm{Kg}$ de N/ha.

Em trabalho realizado com as gramas Estrela Branca e Estrela Roxa, Paciulli (1997) verificou aumento no teor de PB à medida que aumentou as doses de nitrogênio. Os valores de PB para as estrelas Branca e Roxa foram de 11,29 e 16,28\%; 10,83 e 16,96 , respectivamente, para os dois níveis de adubação nitrogenada ( 0 e $400 \mathrm{Kg}$ de N/ha).

O objetivo do presente estudo foi determinar a curva de desidratação da forragem após o corte, em condições de campo, e avaliar a composição química em função da adubação nitrogenada.

\section{Material e Métodos}

O experimento foi realizado no período de janeiro de 2004 a fevereiro de 2004 na Fazenda Experimental de Iguatemi, e no Laboratório de Análises de Alimentos e Nutrição Animal, do Departamento de Zootecnia da Universidade Estadual de Maringá (UEM).

Os dados de temperatura e precipitação, observados durante o período experimental e coletados pelo Posto de Meteorologia da Fazenda Experimental de Iguatemi, são apresentados nas Figuras 1 e 2.

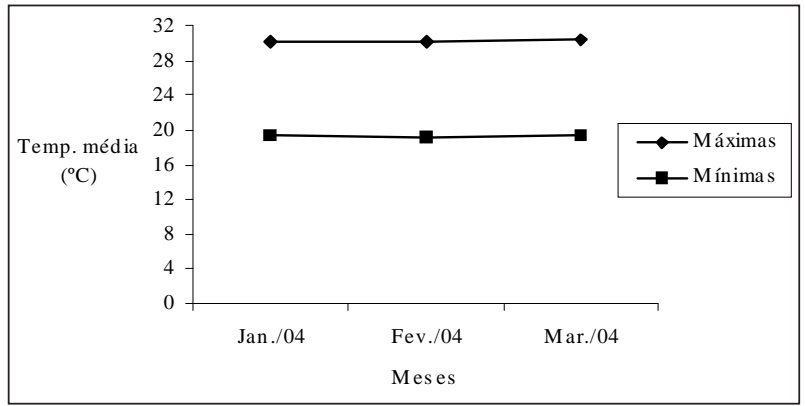

Figura 1. îvíédias de iemperaiuras máximas e míninnas nu período de janeiro a março/2004.

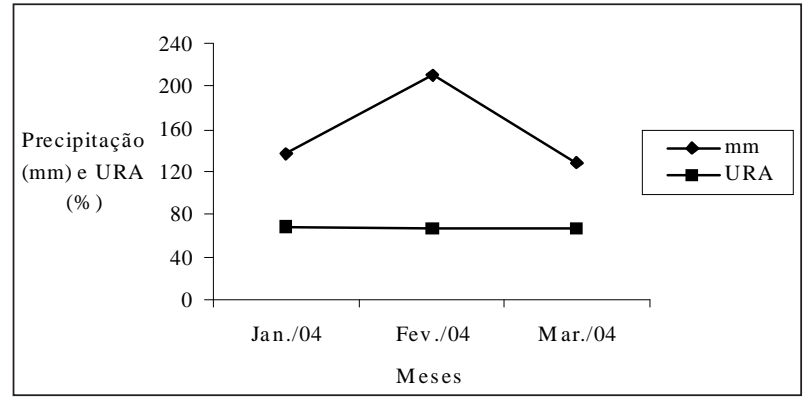

Figura 2. Precipitação (mm) e umidade relativa do ar (URA) registradas no período de janeiro a março/2004.

$\mathrm{O}$ experimento foi conduzido em uma área de aproximadamente dois hectares, já estabelecida, com grama-estrela (Cynodon nlemfuensis Vanderyst), em solo classificado como solo Vermelho Amarelo Distrófico (PARANÁ, 1985). Em 10 de janeiro de 2004, logo após um corte para produção de feno, a área foi dividida em duas áreas equivalentes e realizada a adubação nitrogenada com 50 e $100 \mathrm{Kg}$ / ha na forma de uréia, distribuída a lanço. No dia 08 de fevereiro de 2004, após um período de 28 dias de crescimento foi feito o corte da gramínea com segadora simples de disco e mantida a campo para desidratação até o teor de MS para enfardamento (85 a 90\%).

Durante o período de secagem a campo, foram feitas oito amostragens, sendo uma no tempo zero (no momento do corte), e as outras; 2, 20, 24, 26, 42, 44 e 48 horas após o corte para determinar-se à taxa de desidratação da planta inteira e das frações colmo e folha. Após a amostragem efetuou-se a separação das frações folha e colmo para avaliar os teores de MS. Para a realização da taxa de desidratação, 
utilizou-se um forno de microondas seguindo a metodologia descrita por Silva e Queiroz, (2002).

Determinou-se também a espessura do como, com utilização de um paquímetro digital. Para a medida do diâmetro dos colmos, foram tomadas 20 plantas de cada tratamento, com leitura no primeiro e segundo entre-nós.

Quando a massa de forragem atingiu o teor de MS em torno de $85 \%$, foram confeccionados 10 fardos de cada tratamento e armazenados em galpão apropriado. Para o enfardamento, utilizou-se enfardadora da marca Nogueira, modelo APN 41, de fardos retangulares com peso médio de aproximadamente $10 \mathrm{Kg}$.

Para análise da composição química, após um período de armazenagem de 60 dias, uma amostra de aproximadamente $0,5 \mathrm{Kg}$ de cada fardo foi coletada e posteriormente moída em peneira com malha de $1 \mathrm{~mm}$ e encaminhada ao laboratório, e determinados os teores de matéria seca (MS) a $105^{\circ} \mathrm{C}$, proteína bruta $(\mathrm{PB})$, matéria mineral $(\mathrm{MM})$ e extrato etéreo (EE) de acordo com ASSOCIATION OF OFFICIAL ANALYTICAL CHEMISTS (1990), fibra em detergente neutro (FDN), fibra em detergente ácido (FDA), segundo Van Soest e Robertson, (1985) e a digestibilidade "in vitro" da matéria seca (DIVMS).

Para a determinação da DIVMS, foi empregado o aparelho Daisy Incubator II (Ankon). Esse procedimento propicia maior precisão das análises visto que o ambiente é mantido totalmente anaeróbio, não havendo necessidade da injeção de $\mathrm{CO}_{2}$ durante a fermentação e o pH também é mantido pela adição de soluções tamponantes no início do processo.

Para a coleta do líquido ruminal foi utilizada uma vaca da raça Holandesa, multípara, seca, com peso médio de $550 \mathrm{~kg}$ e munida de fístula ruminal e adaptada com dieta a base de feno de grama- estrela. Para as análises, foram pesados $0,25 \mathrm{~g}$ do material de cada amostra, colocados em sacos de náilon (modelo F57) de uso em Ankon, e acondicionados em jarros, contendo líquido de rúmen e solução tampão. As amostras permaneceram incubadas por 48 horas, quando se acrescentou uma solução de HCl-Pepsina e deixou-se fermentar por mais 24 horas. Posteriormente, os sacos foram retirados do fermentador ruminal, lavados com água destilada, para a retirada dos materiais aderentes ao filtro e após, foram secos em estufa de circulação forçada por $8 \mathrm{~h}$ a $105^{\circ} \mathrm{C}$.

Os tratamentos foram arranjados em um delineamento inteiramente casualizado com dez repetições. Os dados de composição química foram submetidos à análise de variância e as médias, comparadas pelo teste F (5\%), usando-se o Sistema de Análises Estatística - SAEG, desenvolvido pela Universidade Federal de Viçosa (1983), seguindo-se o modelo estatístico:

$$
\mathrm{Y}_{\mathrm{ij}}=\mu+\mathrm{t}_{\mathrm{i}}+\mathrm{e}_{\mathrm{ij}}
$$

Em que:

$\mathrm{Y}_{\mathrm{ij}}=$ Observação j, submetido ao tratamento i;

$\mu=$ Constante geral;

$\mathrm{t}_{\mathrm{i}}=$ Efeito do tratamento $\mathrm{i} ; \mathrm{i}=1,2$;

$\mathrm{e}_{\mathrm{ij}}=$ Erro aleatório associado a cada observação.

\section{Resultados e Discussão}

A taxa de desidratação da planta inteira e das frações colmo e folha da grama-estrela (Cynodon nlemfuensis Vanderyst) adubada com $100 \mathrm{Kg}$ de N/ ha encontra-se na Tabela 1. Pode-se observar que a taxa de desidratação sofre uma oscilação no período de secagem entre 0 e 48 horas, fato este devido ao orvalho durante a noite, reidratando a massa de forragem. No entanto, constata-se que a umidade adquirida durante o período noturno é rapidamente perdida em poucas horas de sol.

Constatou-se que a fração folha apresentou alta perda de água nas duas primeiras horas de secagem (3\%/hora) atingindo 49\% de MS. Após 48 horas de secagem a campo, a fração folha atingiu aproximadamente $90 \%$ de MS, mostrando alta taxa de perda de água. 
A fração colmo, apresentou mais água em relação à fração folha no momento do corte, valores em torno de 30\% de MS contra 43\% de MS para a fração folha. De forma semelhante à fração folha, a fração colmo apresentou alta taxa de desidratação nas duas primeiras horas de secagem (2,5\%/hora) e atingiu valores de 76\% de MS após 48 horas de secagem a campo.

A taxa de desidratação da planta inteira, apresentou comportamento intermediário entre as frações colmo e folha, atingindo valores de $82 \%$ de MS no período final de secagem. Da mesma forma,
Costa e Gomide (1991) avaliando a taxa de secagem dos capins Andropogon gayanus, Brachiaria decumbens, Hyparrhenia rufa, Panicum maximum e Melinis minutiflora, ceifados com oito e doze semanas de crescimento, observaram maior taxa de secagem na fase inicial, ou seja, nas primeiras três horas no campo.

A taxa média de perda de água para a fração folha foi de $0,98 \%$ /hora e de $0,9 \%$ /hora para a fração colmo. Enquanto que a planta inteira apresentou taxa média de desidratação de $0,9 \%$ /hora.

Tabela 1. Teor de matéria seca (MS) da planta inteira (PI), das frações colmo e folha do feno de grama-estrela (Cynodon nlemfuensis) para os diferentes níveis de adubação nitrogenada (100 Kg N/ha e $50 \mathrm{Kg} \mathrm{N} / \mathrm{ha}$ ) em função do tempo (horas) após o corte da gramínea.

\begin{tabular}{ccccccc}
\hline $\begin{array}{c}\text { Momento após } \\
\text { corte } \\
\text { (hora) }\end{array}$ & \multicolumn{9}{c}{ 100 Kg N/ha } & & \multicolumn{2}{c}{50 Kg N/ha } & \\
\cline { 2 - 7 } & PI & Colmo & Folha & PI & Colmo & Folha \\
\hline 0 & 40 & 30 & 43 & 37 & 32 & 47 \\
2 & 46 & 37 & 49 & 42 & 38 & 54 \\
20 & 51 & 48 & 59 & 57 & 46 & 58 \\
24 & 73 & 60 & 90 & 67 & 64 & 89 \\
26 & 65 & 60 & 82 & 67 & 58 & 84 \\
42 & 58 & 56 & 70 & 58 & 51 & 61 \\
44 & 72 & 60 & 88 & 65 & 60 & 90 \\
48 & 82 & 76 & 90 & 85 & 71 & 92 \\
\hline
\end{tabular}

A taxa de desidratação da planta e das frações colmo e folha da grama-estrela adubada com $50 \mathrm{Kg}$ de N/ha encontra-se na Tabela 1. A fração folha apresentou valor de $47 \%$ de MS no momento do corte e $92 \%$ de MS após 48 horas de secagem a campo, apresentando perda de água de 3,5\%/hora nas duas primeiras horas após o corte, mostrando que este componente apresenta rápida perda de água.

A fração colmo apresentou maior teor de umidade no início do período de secagem (32\% de MS), atingindo valor de $71 \%$ de MS após um período de 48 horas de secagem, com maior perda de água duas horas após o corte (3\%/hora). Isto demonstra que essa fração apresenta maior dificuldade em perder água comparada à fração folha.
Constatou-se, que a planta inteira apresentou valores de $37 \%$ de MS no momento do corte. No momento do enfardamento atingiu $85 \%$ de MS, valores estes considerados ideais para o enfardamento.

A taxa média de perda de água para a fração folha foi de $0,94 \% /$ hora, enquanto que para o colmo foi de $0,81 \%$ /hora. Já a planta inteira apresentou taxa média de desidratação de 0,90\%/hora.

O período total de secagem a campo foi de 48 horas para os dois níveis de adubação estudados, e isto se deve à alta temperatura e baixa umidade relativa do ar (Figura 1 e Figura 2, respectivamente), mostrando que estas variáveis climáticas são de 
extrema importância para reduzir as perdas e obter um feno de alto valor nutritivo.

Os níveis de adubação não exerceram influência na perda de água da gramínea, visto que o padrão da taxa de desidratação da planta para os diferentes níveis de adubação (Tabela 1) mostrou-se muito semelhante, com taxa média de perda d'água de 0,90\%/hora. Estes dados estão de acordo com Ferrari Júnior et al. (1993), os quais não encontraram diferença na perda de água da grama Coast-cross, submetido à adubação com $100 \mathrm{Kg} / \mathrm{N} / \mathrm{ha}$. Estes autores observaram maiores perdas de água durante as primeiras quatro horas de secagem em estufa a $65^{\circ} \mathrm{C}$.

Segundo Holt e Conrad (1986) os fatores como cerosidade da cutícula, pilosidade, abertura e fechamento de estômatos e proporção de folhas podem ter influência no processo de desidratação da forrageira.

A espessura do colmo pode influenciar negativamente na taxa de secagem da gramínea, haja vista que esta fração apresenta maior quantidade de água e menor rapidez na perda de água comparada à fração folha e planta inteira. A Figura 3 mostra que o diâmetro do colmo foi ligeiramente superior para o nível de adubação de $100 \mathrm{Kg}$ N/ha (1,98 mm) comparado ao nível de $50 \mathrm{Kg} \mathrm{N} / \mathrm{ha}(1,95 \mathrm{~mm})$. Isto pode ser explicado em parte, pelo maior desenvolvimento da planta submetida ao maior nível de adubação nitrogenada. Porém, acredita-se que um maior intervalo entre a aplicação do nitrogênio e o corte pode acentuar esta diferença. As plantas adubadas com $100 \mathrm{Kg}$ de N/ha apresentaram menor teor de MS (82\%) 48 horas após o corte em relação à adubação com $50 \mathrm{Kg}$ de N/ha (85\%), o que pode ser devido ao maior diâmetro do colmo daquelas plantas. Estes resultados estão de acordo com o mencionado por Jobim et al. (2001), os quais encontraram uma correlação negativa entre o diâmetro de colmo e a taxa de desidratação em gramíneas do gênero Cynodon.

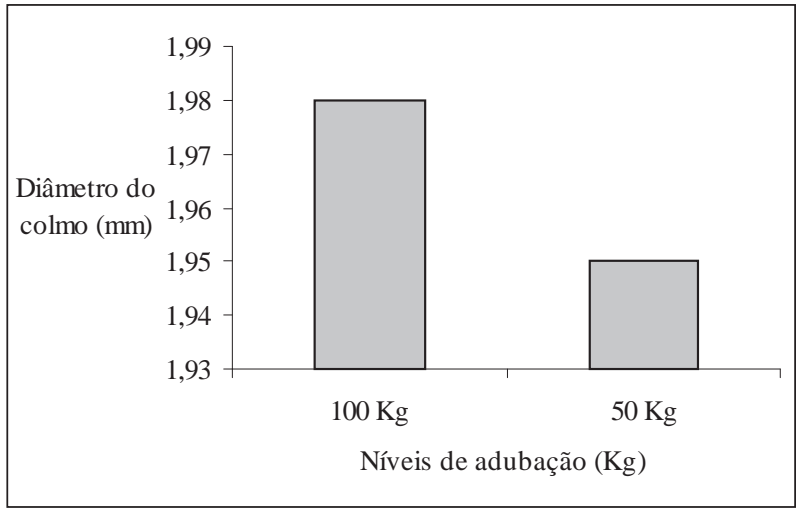

Figura 3. Diâmetro médio dos colmos da grama-estrela em função de diferentes níveis de adubação.

Na Tabela 2 estão apresentados os dados referentes à composição químico-bromatológica do feno de grama-estrela (Cynodon nlemfuensis Vanderyst) submetidos à adubação com 50 ou 100 $\mathrm{Kg}$ de N/ha.

Os teores de MS, não diferiram $(\mathrm{P}>0,05)$ entre os tratamentos após 60 dias de armazenagem (Tabela 2). O valor médio observado neste experimento foi de aproximadamente 90,6\% de MS, sendo este adequado para que não ocorram perdas por atividade microbiológica durante a armazenagem, garantindo assim um material de boa qualidade nutricional a ser fornecido aos animais.

Já em relação à proteína, a planta adubada com $100 \mathrm{Kg}$ de nitrogênio teve teor de PB superior $(\mathrm{P}<0,05)$ ao tratamento com $50 \mathrm{Kg}$ de nitrogênio. Esses resultados estão de acordo com as informações obtidas no trabalho de Assis (1997), em que todas as gramas estudadas tiveram incremento no teor de PB em função do incremento na adubação nitrogenada. Outros trabalhos na literatura também mostram o efeito positivo da adubação nitrogenada no teor de PB (ALVIM; RESENDE; BOTREL, 1996; CECATO et al., 2001), explicado pelo aumento na formação de folhas jovens. 
Tabela 2. Teor de matéria seca (MS), proteína bruta (PB), fibra em detergente neutro (FDN), fibra em detergente ácido (FDA), extratro etéreo (EE), matéria mineral (MM), digestibilidade in vitro da matéria seca (DIVMS) e digestibilidade in vitro da proteína bruta (DIVPB), do feno de grama-estrela (Cynodon nlemfuensis) em função do nível de nitrogênio.

\begin{tabular}{lcccccccc}
\hline $\begin{array}{l}\text { Níveis de N } \\
\text { Kg/há }\end{array}$ & MS & PB & FDN & FDA & EE & MM & DIVMS & DIVPB \\
\hline 50 & 90,5 & $7,4^{\mathrm{a}}$ & 81,7 & 41,9 & 0,80 & 4,2 & 61,7 & 65,5 \\
100 & 90,7 & $8,5 \mathrm{~b}$ & 83,5 & 42,8 & 0,78 & 4,1 & 61,6 & 60,1 \\
CV\% & 1,4 & 7,9 & 2,9 & 3,5 & 4,1 & 8,5 & 6,8 & 6,9 \\
\hline
\end{tabular}

Médias seguidas de letras diferentes na coluna, diferem pelo teste F 5\%

Para os teores de FDN, os níveis de adubação não influenciaram $(\mathrm{P}>0,05)$, embora, o tratamento com $100 \mathrm{Kg}$ de $\mathrm{N} / \mathrm{ha}$ apresentou 1,8 pontos percentuais a mais que o tratamento com $50 \mathrm{Kg}$ de $\mathrm{N}$. Isto pode ser explicado pelo maior desenvolvimento da fração colmo em função da maior disponibilidade de nitrogênio. Estes resultados estão em concordância com os apresentados por Alvim, Resende e Botrel (1996), que, em experimento com grama Coast-cross e utilizando nitrogênio até $750 \mathrm{Kg} /$ ha, não observaram alterações nos teores de FDN. Já, Rocha et al. (2001) observaram decréscimo no teor de FDN com o aumento da adubação nitrogenada, variando de 0 a $400 \mathrm{Kg}$ de N/ha. A literatura mostra resultados variáveis para o teores de FDN e FDA para plantas fertilizadas com nitrogênio. Esta variação ocorre em função da espécie forrageira, da dose de nitrogênio aplicado, do intervalo entre a aplicação do fertilizante e principalmente o intervalo de corte.

Também para os teores de FDA, não houve diferença $(\mathrm{P}>0,05)$ entre os tratamentos, obtendo-se valor médio de $42 \%$ na MS. Resultados semelhantes aos deste trabalho foram encontrados por Rocha et al. (2002), que não encontraram respostas para gramíneas do gênero Cynodon, quando usaram diferentes doses de N/ha (0, 100, 200 e $400 \mathrm{Kg}$ ), com intervalos entre cortes de 42 dias, alcançando teores médios de FDA de 40,18\%. Entretanto, Belesky et al. (1991) observaram redução no teor de FDA, da gramaBermuda, quando adubado com nitrogênio.

Os teores de EE não diferiram $(\mathrm{P}>0,05)$ entre os tratamentos estudados, variando de 0,78 a 0,80 para os níveis com 50 e $100 \mathrm{Kg}$ de N/ha. De acordo com Church (1988), a grande maioria das forrageiras apresenta pequeno teor de EE em sua constituição, podendo alcançar até 3,5\% na MS. Em trabalho realizado com grama-estrela em regime de pastejo, Porto (2005) encontrou valores de EE variando de 1,29 à $1,53 \%$. Isto mostra que normalmente ocorre variação nos teores de EE nas forrageiras.

Quanto ao teor de MM, não ocorreu diferença $(\mathrm{P}>0,05)$ entre os níveis de adubação nitrogenada, com valor médio de $4,15 \%$, valor normalmente observado para a grama-estrela.

Não constatou-se efeito da adubação nitrogenada $(\mathrm{P}>0,05)$ sobre a DIVMS, o que pode ser explicado pela semelhança entre a maioria dos componentes da MS, principalmente da fração fibrosa. Van Soest (1994) relata que a concentração de proteína bruta está associada positivamente com a digestibilidade e esta declina com o aumento na idade da planta, mas a adubação nitrogenada eleva o conteúdo de proteína bruta, sem alterar significativamente a digestibilidade. Estes resultados de DIVMS estão de acordo com os obtidos por Belesky et al. (1991), que estudaram grama Bermuda sob quatro níveis de nitrogênio (60, 120, 240 e $360 \mathrm{Kg}$ de $\mathrm{N} / \mathrm{ha}$ ) e observaram que a digestibilidade in vitro da matéria seca não foi afetada pelos níveis de nitrogênio. Da mesma forma, em trabalho realizado por Cecato et al. (2001) com gramíneas do gênero Cynodon, a adubação nitrogenada não influenciou na digestibilidade in vitro da matéria seca e da matéria orgânica. 
Embora o feno produzido no tratamento com aplicação de $100 \mathrm{Kg}$ de N/ha apresentou maior teor de PB, não houve efeito para os valores de DIVPB $(\mathrm{P}>0,05)$ entre os tratamentos, obtendo-se o valor médio de $63 \%$ na MS. Este resultado está próximo ao encontrado por Gonçalves et al. (2003), que obtiveram valor de $62 \%$, para feno de Tifton 85 cortado com 28 dias de rebrota.

\section{Conclusões}

A curva de desidratação da grama-estrela não foi influenciada pela quantidade de nitrogênio aplicado, com maior taxa de secagem nas primeiras duas horas após o corte.

A adubação com $100 \mathrm{Kg}$ de nitrogênio/ha melhorou o teor de PB do feno da grama-estrela, porém não afetou os componentes da fração fibra, não resultando em aumento na qualidade nutricional do feno.

\section{Referências}

ALVIM, M. J.; RESENDE, H.; BOTREL, M. A. Efeito da frequiência de cortes e do nível de nitrogênio sobre a produção e qualidade da matéria seca do "Coast-cross". In: WORKSHOP SOBRE O POTENCIAL FORRAGEIRO DO GÊNERO CYNODON, 1., 1996, Juiz de Fora. Anais... Juiz de Fora: Embrapa/CNPGL, 1996. p.45-55.

ASSIS, M. A. Digestibilidade in vitro, degradabilidade in situ e composição química de gramíneas do gênero Cynodon submetidas ou não a adubação nitrogenada. 1997. Dissertação (Mestrado em Zootecnia) Universidade Estadual de Maringá, Maringá.

ASSOCIATION OF OFFICIAL ANALYTICAL CHEMISTS. Official methods of analysis. 15. ed. Arlington: AOAC, 1990. v.1

BELESKY, D. P.; PERRY, D. H.; WINDHAM, W. R.; MATHIAS, E. L.; FEDDERS, J. M. Productivity and quality of bermudagrass in a cool temperate environment. Agronomy Journal, Madison, v.83, n.5, p.810-813, 1991.

CECATO, U. Influência da freqüência de corte, níveis e formas de aplicação de nitrogênio na produção $e$ composição bromatológica do capim aruana. (Panicum maximum jacq cv. Aruana). 1993. Tese (Doutorado em Produção Animal) - Universidade Estadual Paulista, Jaboticabal.
CECATO, U.; SANTOS, G. T.; MACHADO, M. A.; GOMES, L. H.; DAMACENO, J. C.; RIBAS, N. P.; MIRA, R. T.; CANO, C. C. P. Avaliação de cultivares do gênero Cynodon com e sem nitrogênio. Acta Scientiarum, Maringá, v.23, n.4, p.781-788, 2001.

CHURCH, D. C. El Ruminante: Fisiologia digestive y nutrition. 3.ed. Oxford: Oxford press Inc, 1988.

COSTA, J. L.; GOMIDE, J. A. Drying rates of tropical grasses. Tropical Grasslands, Brisbane, v.25, n.4, p.325-332, 1991.

FERRARI JÚNIOR, E.; RODRIGUES, L. R. A.; REIS, R. A.; COAN, O.; SCHUMMAS, E. A. Avaliação do capim Coastcross para a produção de feno em diferentes idades e níveis de adubação de reposição. Boletim Indústria Animal, Nova Odessa, v.50, n.2, p.137-145, 1993.

GOMIDE, J. A. Características de plantas forrageiras a ser fenada. Informativo Agropecuário, Belo Horizonte, v.6, n.64, 1980. p.6-8.

GONÇALVES, G. D.; SANTOS, G. T.; JOBIM, C. C.; DAMASCENO, J. C.; CECATO, U.; BRANCO, A. F. Determinação do consumo, da digestibilidade e das frações protéicas e de carboidratos do feno de tifton 85 em diferentes idades de corte. Revista Brasileira de Zootecnia, Viçosa, v.32, n.4, p.804-813, 2003.

HADDAD, C. M.; CASTRO, F. G. F. Produção de feno. In: SIMPÓSIO SOBRE MANEJO DA PASTAGEM, 15., 1998, Piracicaba. Anais... Piracicaba: FEALQ, 1998. p.151-172.

HILL, G. M.; GATES, R. N.; BURTON, G. W. Forage quality and grazing steer performance from Tifton 85 and Tifton 78 Bermudagrass pastures. Journal of Animal Science, Champaign, v.71, n.12, p.3219-3225, 1993.

HOLT, E. C.; CONRAD, B. E. Influence of harvest frequency and season on Bermudagrass cultivar yield and forage quality. Agronomy Journal, Madison, v.78, n.3, p.433-436, 1986.

JOBIM, C. C.; LOMBARD, L.; GONÇALVES, G. D.; LOMBARDI, L.; GONÇALVES, G. D.; CECATO, U.; SANTOS, G. T.; CANTO, M. W. Desidratação de cultivares de Cynodon spp. durante o processo de fenação. Acta Scientiarum, Maringá, v.23, n.4, p.795-799, 2001.

MARTIM, R. A. Doses de nitrogênio e de potássio para a produção, composição e digestibilidade dos capins Coastcross e Tifton $85 \mathrm{em}$ um latossolo vermelhoamarelo. 1997. Dissertação (Mestrado em Agronomia) Escola Superior de Agricultura Luiz de Queiroz, Piracicaba.

PACIULLI, A. S. Efeito de diferentes épocas de corte e doses de nitrogênio sobre a produção, composição química e digestibilidade "in vitro" de três gramíneas tropicais do gênero Cynodon. 1997. Dissertação (Mestrado em Forragicultura e Pastagem) - Universidade Federal de Lavras, Lavras. 
PARANÁ. Secretaria da Agricultura e do Abastecimento. Mapeamento dos municípios do Estado do Paraná. Curitiba, 1985.

PORTO, P. P. Produção de leite de vacas mestiças holandês $x$ zebu em forrageiras tropicais manejadas em lotação rotacionada. 2005. Tese (Doutorado em Zootecnia) - Universidade Estadual de Maringá, Maringá.

ROCHA, G. P.; EVANGELISTA, A. R.; LIMA, J. A.; ROSA, B. Adubação nitrogenada em gramíneas do gênero Cynodon. Ciência Animal Brasileira, Goiânia, v.3, n.1, p.1-9, 2002.

ROCHA, G. P.; EVANGELISTA, A. R.; PAIVA, P. C. A. FREITAS, R. T. F.; SOUZA, A. F., GARCIA, R. Digestibilidade e fração fibrosa de três gramíneas do gênero Cynodon. Ciência Agrotécnica, Lavras, v.25, n.2, p.396407, 2001.
SILVA, D. J.; QUEIROZ, A. C. Análise de alimentos: métodos químicos e biológicos. 3.ed. Viçosa: UFV, 2002.

UNIVERSIDADE FEDERAL DE VIÇOSA. Manual de utilização do programa SAEG (Sistemas de Análises Estatísticas e Genéticas). Viçosa: UFV, 1983.

VAN SOEST, P. J. Nutritional ecology of the ruminant. 2.ed. Corvalis: Cornell University Press, 1994.

VAN SOEST, P. J., ROBERTSON, J. B. Analysis offorages and fibrous foods: a laboratory manual for animal science. Corvalis: Cornell University Press, 1985.

WERNER, J. C. Adubação de pastagens. Nova Odessa: Instituto de Zootecnia, 1984. (Boletim Técnico, n.18). 
